\title{
Implementation of a flexible Major Vacation Toll-free Program for small passenger vehicles in China
}

\begin{abstract}
C The Author(s) 2017. Published by Higher Education Press. This is an open access article under the CC BY license (http:// creativecommons.org/licenses/by/4.0)
\end{abstract}

On July 24, 2012, the State Council of the People's Republic of China implemented "a toll-free program for small passenger vehicles during major vacations ${ }^{1)}$. In the several months that followed, local governments issued implementation articles. The current Major Vacation Tollfree Program for small passenger vehicles (MVTP) pioneers the concept (Xu and Gao, 2016), "Benefaction to People." The current MVTP has received considerable support from the nation. According to the survey ${ }^{2}$, approximately $85.19 \%$ of respondents consider the MVTP an important measure to benefit people, which stimulates economic growth, boosts domestic demand, and improves the government's social satisfaction.

China's highways are undergoing rapid development. The State Council of China approved the planning the National Trunk Highway System (NTHS) in December 2004. This plan aimed to build an expressway network of $85000 \mathrm{~km}$ over three decades, connecting all provincial capitals and cities with over 200000 residents. The plan requires huge investment in terms of budget. Furthermore, nearly all expressways in the NTHS are toll roads run by firms owned by central/local governments ( $\mathrm{Xu}$ et al., 2015). The toll-free highway program covers all tolled roads, bridges, and tunnels and involves motorcycles and small passenger vehicles with no more than seven seats. Major vacations include the Spring Festival, Tomb

Received October 23, 2017

Meng XU ( $ه)$, Ziyou GAO

State Key Laboratory of Rail Traffic Control and Safety, Beijing Jiaotong University, Beijing 100044, China

E-mail: mengxu@bjtu.edu.cn
Sweeping Day, Labor Day, and National Day. The free period starts from 00:00 of the first day and ends at 24:00 of the last day of such vacations.

Although the current MVTP receives considerable support from the public, the toll-free period also brings certain challenges, such as the surge of tourists in hot tourism areas, heavy traffic congestion on highways, and fast improved traffic accidents. Instead of enjoying their vacations, tourists have to spend ample time on the road, resulting in a social inefficiency (Bao et al., 2017). According to highway statistics of Jingjinji in 2013 and $2014^{3)}$, the number of daily accidents per year is 10.5 . During holidays, the number is at 27.8 , and during national vacations, the number is at 52.4. According to the statistics of the Transport Department of Shanxi province, $90 \%$ of accidents happen on highways during the Tomb Sweeping vacation and are caused by private cars. The toll-free program greatly promotes the growth of traffic flow, cars accounts for $89 \%$ of them, and gridlock was caused at National Day of 2012 (Li and He, 2015).

Considering the challenges faced by the current MVTP, we propose a Flexible Major Vacation Toll-free Program for small passenger vehicles (FMVTP). The difference is that the fixed toll-free period in the MVTP can be adjusted by small passenger vehicle owners. Owners could apply the toll-free periods yearly based on their travel demand. However, owners should pay the toll normally if they have already availed themselves of the benefit and continue traveling during these major holidays. To continue the current MVTP, the excused vehicles i.e. motorcycles and small passenger vehicles with no more than seven seats, keep current definition.

1) The Central People's Government of People's Republic of China (2012). Implementation of toll free program for small passenger vehicles during major holidays.

2) Questionnaire on effect of "Toll Free Program for Small Passenger Vehicles during Major Holidays". https://www.wjx.cn/report/2442763.aspx

3) Big data provides guidance for travelling during the national holiday. http://www.zgg.org.cn/bwdj_5137/gbwjgdwzzq/qgrdcwjg_9513/zfzx/201510/ t20151012 546074.html 
From the overview of the implementation of the FMVTP, the following three points should be well considered:

1. Alternative toll-free period choice: The four fixed toll-free periods, namely, Spring Festival, Tomb Sweeping Day, Labor Day, and National Day, can be adjusted freely to other periods. However, the fixed toll-free periods cannot be aggregated or divided and will expire the next year. For instance, the four toll-free periods in 2016 were the Spring Festival (Seven days from February 7 to 13), Tomb Sweeping Day (Three days from April 2 to 4), Labor Day (Three days from April 30 to May 2), and National Day (Seven days from October 1 to 7). The applicant could choose their four toll-free periods within 2016, which is from 00:00 1st January 2016 to 24:00 31st December 2016 , with respect to the holidays' seven- and three-day durations. Neither aggregation nor any separation of the four periods are permitted. The other limitations of the FMVTP follow those of the current MVTP.

2. Development of an integrated management platform: An integrated FMVTP management platform must be developed to guarantee the smooth implementation of the FMVTP. Such a platform can extend from the current highway toll management system. This function would be under the guidance of national highway administration. The tentative implementation can also start with current vehicles with ETC (Electronic Toll Collection System) tags. Moreover, for the convenience of application, clients of the management platform would cover mobility client, mobile phone APP, and call application.

3. Strengthening of the communication and cooperation between local traffic management bureaus and the highway management department: With the FMVTP, the transport authority is given a chance to improve the management and supervision of the highway. The highway management department should strengthen its coordination with the transport authority and maintain the smooth implementation of the FMVTP. During the implementation, the department will record each vehicle using the highway and provide a database for effective vehicle management, potential policy evaluation, and further improvement. Vehicles that have already availed themselves of the four toll-free periods and still continue use the highway should pay the toll within a fixed period (e.g., 1 month). Such vehicles should also pay the fine for overdue toll. The exact management scheme can be borrowed from road pricing management practices in certain developed countries, such as the London road pricing management measure in the UK.

The implementation of the FMVTP will bring certain benefits. For instance, the implementation will push the development of "the Internet + Highway," which is crucial for highway management in China. The FMVTP will also mitigate highway traffic congestion during major vacations, especially when passing the toll booth. The total vehicle number during major holidays will also be decreased. The FMVTP also coordinates sector development between tourism and the highway, which benefits both sectors. Examples of such benefits include making the public flexible in arranging their vacations, to incentivizing tourism consumption of non-holidays and mitigating traffic congestion in tourist areas and highways during major holidays. Moreover, the FMVTP can improve population benefits and social equity. Some people must still be on duty during the major holidays, such as policemen, doctors, and highway staff. They will benefit from the implementation of the FMVTP with Alternative toll-free period choice.

Acknowledgements This paper was jointly supported by the National Natural Science Foundation of China (Grant Nos: 71422010, 71621001 and 71771015)

\section{References}

Bao Y, Xiao F, Gao Z H, Gao Z Y (2017). Investigation of the traffic congestion during public holiday and the impact of the tollexemption policy. Transportation Research Part B: Methodological, 104: $58-81$

Li Y, He Q (2015). Evaluating the Major Holiday's Toll-Free Program for small passenger vehicles in China: a case study of Shanghai. 15th COTA International Conference of Transportation Professionals, 3694-3703

Xu M, Gao Z Y (2016). The flexible major vacation toll-free program for small passenger vehicles benefits for people. Internal Reference of National Natural Science Foundation of China, 1-7

Xu M, Grant-Muller S, Gao Z Y (2015). Evolution and assessment of economic regulatory policies for expressway infrastructure in China. Transport Policy, 41: 42-49 